\title{
COMPREHENSIVE ACCESS PLANNING IS KEY TO ECONOMIC SUSTAINABILITY
}

\author{
CHRIS HUFFMAN P.E. and MICHELLE WINKELMANN P.E.* \\ Huffman Corridor Consulting, LLC; 1201 Wakarusa E-1, Lawrence, Kansas USA 66049 \\ Tel: (888) 804-4367, E-mail: hcc@sunflower.com \\ *Parsons Brinkerhoff; 225 N. Market Ste 350, Wichita, Kansas USA 67202 \\ Tel: (316) 263-6121, E-mail: winkelmann@pbworld.com
}

\begin{abstract}
In developing an access management plan it is necessary to investigate the balance between current and future land uses, and existing and planned transportation capacity. Land-uses and transportation networks exist in a demand/supply relationship just like any economic system. The market penetration of the land uses in the area will degrade over time if inappropriate access connections are allowed to undermine the safety and efficiency of the transportation network.

An area-wide access management plan was developed by a thorough analysis of future traffic generation and distribution characteristics. A retrofit of the existing arterial highway to a freeway class facility, with one way pair frontage roads, was analyzed and points of interchange and access to this freeway system were identified. Once interchanging and intersecting roadways were identified, queuing analyses were conducted to quantify the required access control "offsets". Intersection nodes at these offsets were then established to identify where "access" roads could intersect.

With a transportation system framework in place, a land use plan was developed. The foundation of an implementation plan was developed to allow for cooperation and coordination between State, Regional, and Local governments. Execution of this plan will provide for improved economic sustainability and public safety.
\end{abstract}

\section{$1 \quad$ INTRODUCTION}

1.1 Corridor Location and Market Area Characteristics

The Subject corridor is a four-lane divided arterial highway approximately five kilometers long located on the eastern extreme of the Wichita, Kansas metropolitan area in the central portion of the United States. The corridor is characterized by a variety of land uses of varying ages and with varying economic life spans. Economic development of the corridor happened

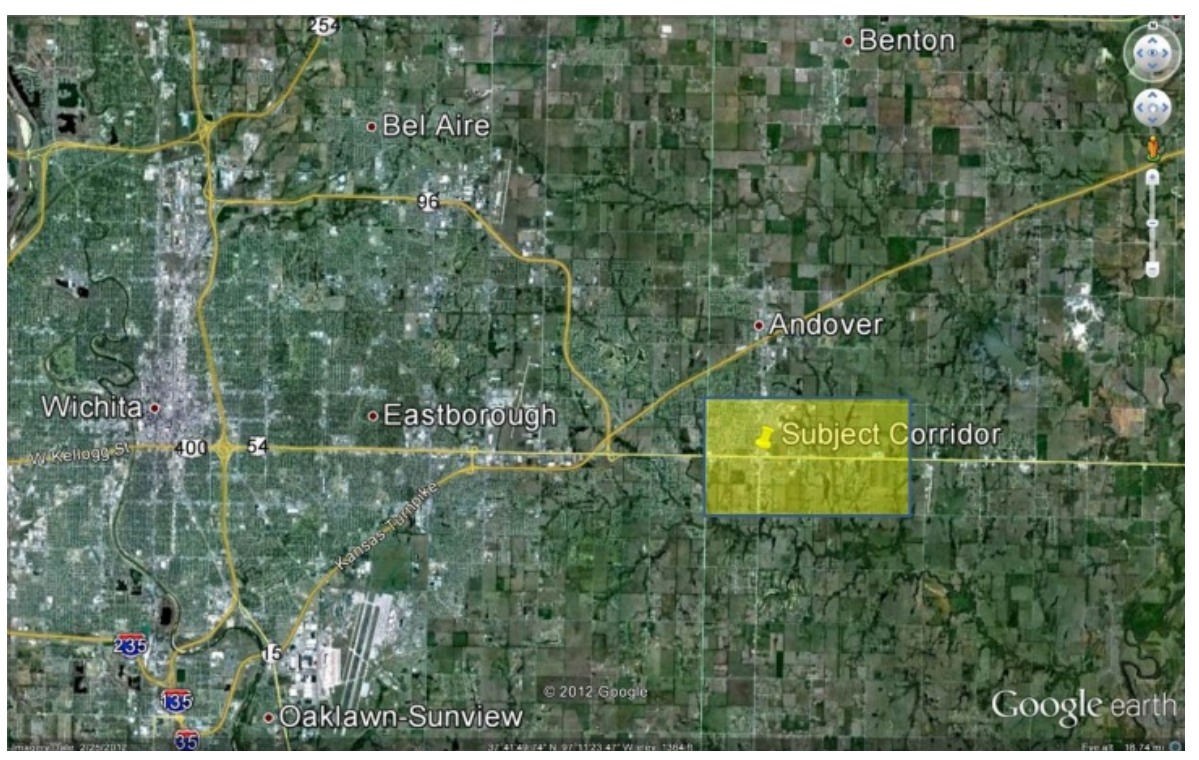

Figure 1: Corridor Location 
haphazardly and without comprehensive planning requirements until 1999 when State, regional, and local authorities adopted the first corridor access plan, and developed a corridor overlay zoning district.

This corridor is undergoing systematic conversion from a four-lane expressway to a sixlane freeway from the metropolitan center of Wichita outward both east and west. The costs of these conversions have become prohibitively high given the lack of coordination of land-use and transportation issues. Right-of-way and business relocation expenses have contributed to costs of millions of dollars per kilometer in the conversion of this corridor. A more complete and proactive corridor planning process is required that simultaneously considers both land-use and transportation issues; and that considers access management, which is the valve through which traffic flows from roadway to private property and back again.

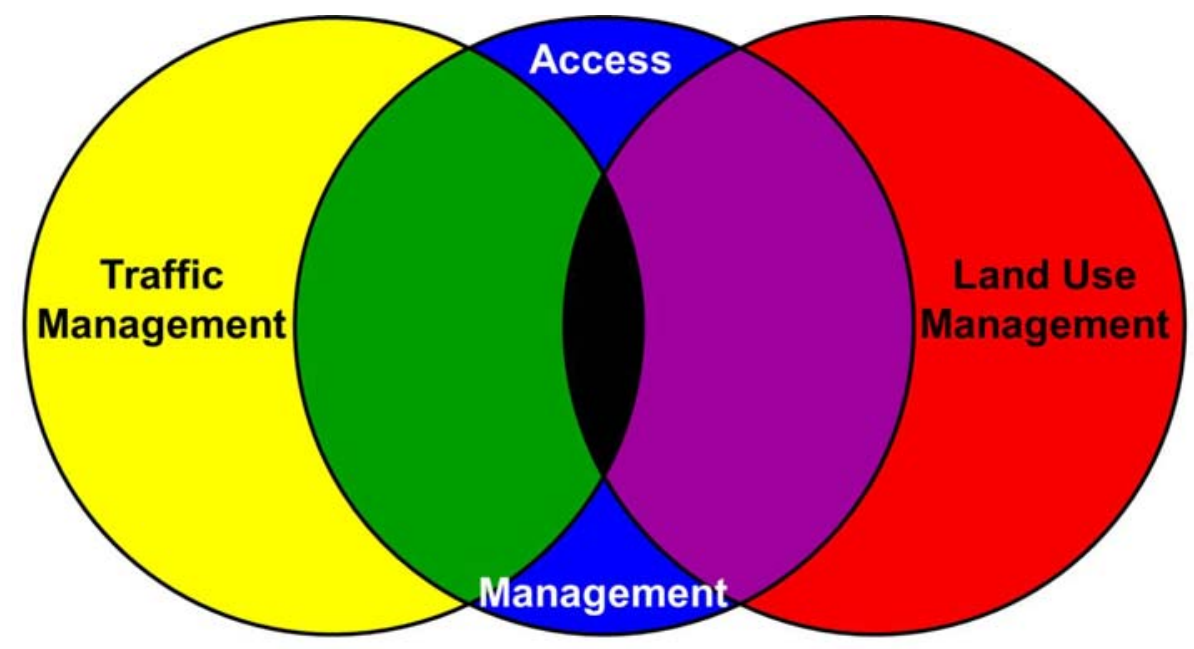

Figure 2: Land-Use/Transportation Interaction

\subsection{Current Land Uses and Development Patterns}

Land uses within the project area include retail uses such as fuel stations, restaurants, grocery and other merchant shops. There are also some "light" industrial uses including warehouses and light manufacturing facilities. Finally, there are civic uses such as a public golf course, and a community
recreation center. This "commercial" corrygre 3 : Lat.Sizize and Dimensions
transitions to residential uses both

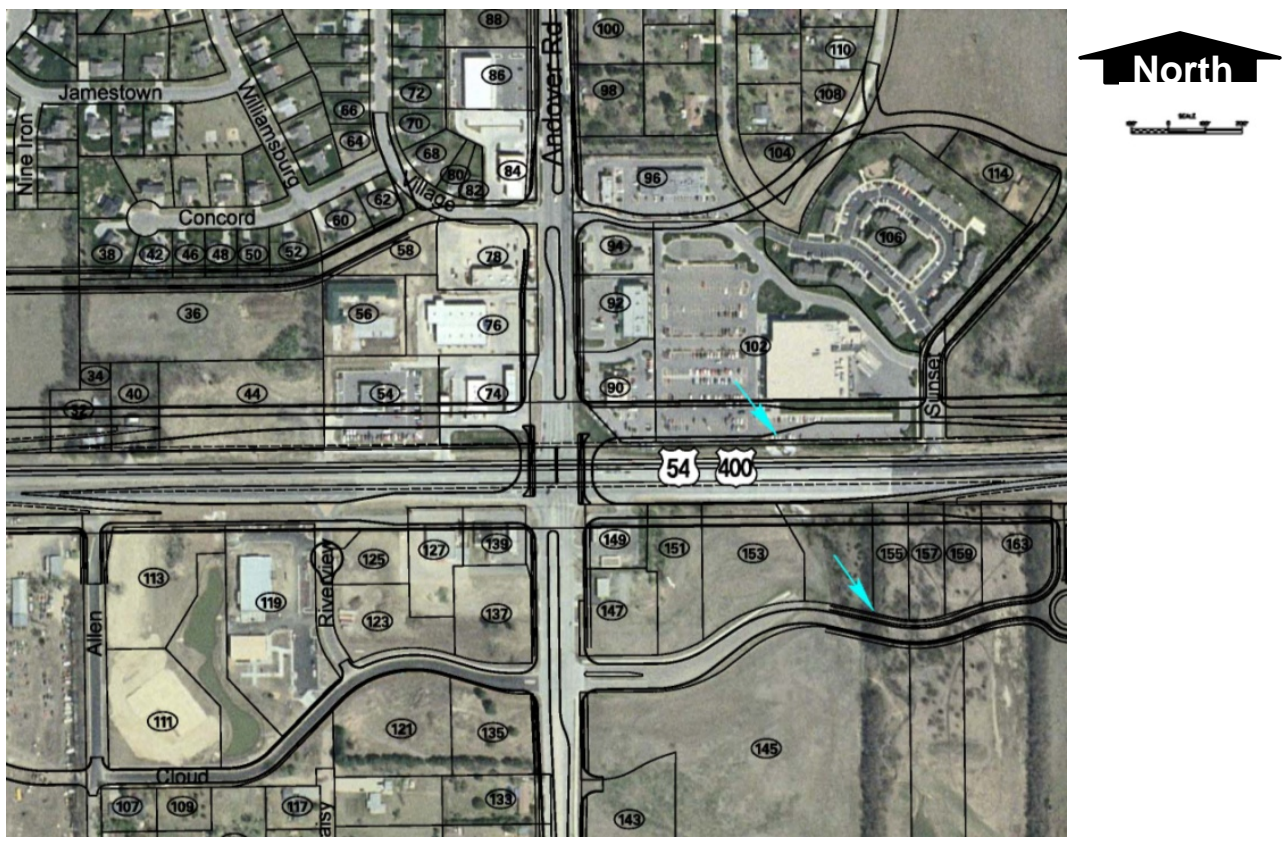
north and south of the corridor. The land uses within the project footprint have developed over approximately 30 years with little thought to comprehensive planning. As a result, 
there are widely varying lot sizes and on-site traffic circulation patterns. The current land use patterns are presented here because one of the principal barriers to access management retrofit is the perceived disruption to existing land uses. The desired freeway retrofit of the project area will, however, likely take 20 years or more to accomplish. In that time, with the exceptions being the golf course and the community recreation center, the current land uses will be near (or beyond) their economic lives and ready for redevelopment. Having a transportation retrofit plan in place when market demand dictates re-development allows progress toward the ultimate vision while simultaneously assuaging concerns regarding economic disruptions.

\subsection{Social Priorities and Goals}

An extensive public involvement effort established the priorities of the community and of the regulatory partners responsible for the corridor. The community is largely a "bedroom" town (people live here, but commute to work), and is proud of its small town environment and quality of life. The community understands that the freeway retrofit is eventually necessary, and that the continuing development of the corridor is inevitable. However, as this occurs, the community is determined to accomplish the following:

- The community is determined to increase, and sustain a diverse tax base.

- The community is determined to protect its "home-town" heritage.

- The community is determined that a freeway corridor will not constitute a "concrete river" dividing the community.

Simultaneously, the need for the regional freeway corridor to move large volumes of traffic at higher speeds is a priority of state and regional authorities.

\section{FUTURE TRANSPORTATION SYSTEM}

2.1 Functional Classifications and Measures of Effectiveness

One of the principle challenges with long range transportation planning in the central portion of the United States is that population densities are generally low. This has resulted in arterial class corridors being forced to serve functions of local access as well as through movement. One of the principle purposes of this study was to identify a complete system of freeway/arterial/collector/local class facilities that can, as a system, serve the

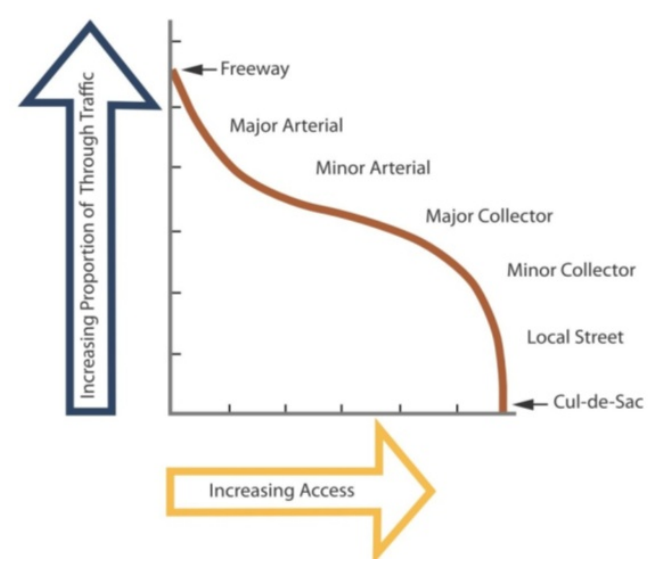

Figure 4: Functional Classification needs of through movement and local access safely and efficiently. Measures of effectiveness identified during the public involvement process include the safety of the transportation system, but also include the market penetration of the corridor, and the economic sustainability of the land uses along the corridor.

\subsection{Cross-sections and Streetscapes}

From a series of public meetings, each utilizing a variation of a nominal group technique, and given that the freeway would be six lanes and the one-way pair frontage roads two lanes, a series of cross sections and streetscapes was developed. 


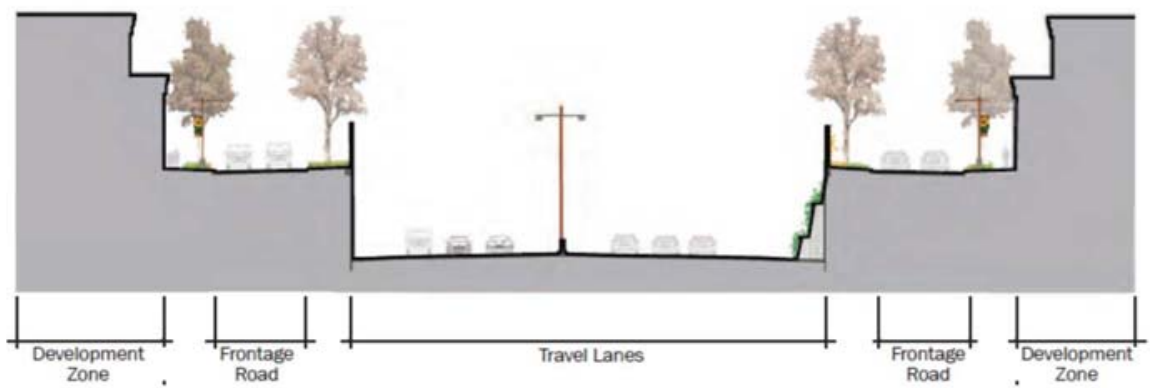

Figure 5: Freeway System Cross-Section

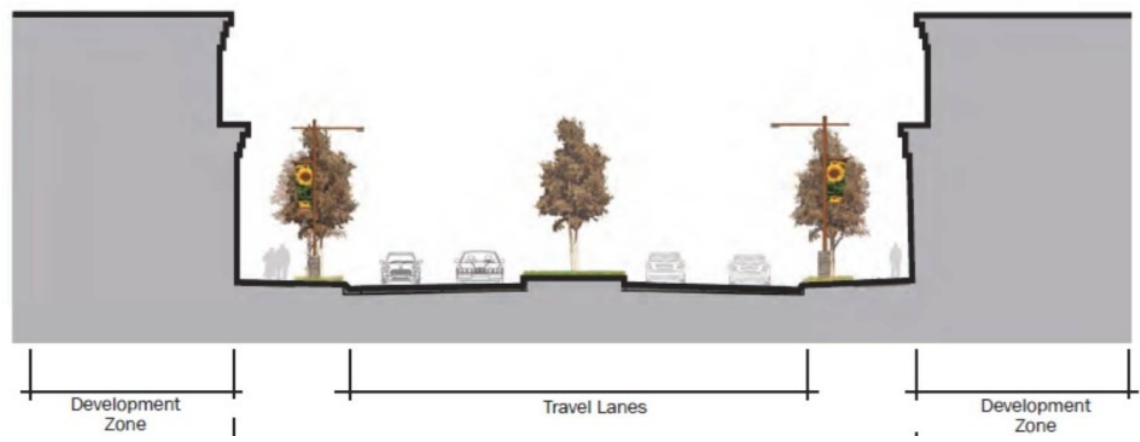

Figure 6: Access Road Cross-Section

The public participants, government officials, business owners, and other key stakeholders expressed strong resistance to massive, multi-lane pavement cross-sections dominating the community. The social priorities of lifestyle (pedestrian amenities, green-space, etc.) meant that maximum cross-sections of the various roadway classifications had to be established first. These cross-sections may then be analyzed for its maximum theoretical capacity. This maximum theoretical capacity then (through trip generation data) allows a land-use plan to be developed (through numerous iterations) that does not generate more capacity demand than can be supplied by the transportation system. This is a significant departure from traditional transportation planning, where future demand is estimated based upon historical patterns, then designs are made to meet those demands.

\subsection{Capacity Constrained Traffic Forecasts}

Once cross-sections are identified, and minimum acceptable levels of service are established, maximum future traffic demand that can be tolerated is analyzed. The Team utilized a VISSIM model to couple existing traffic count data with predicted growth rates to establish a "maximum" network traffic load. Three interchange locations were established, and two other locations where arterials overpass the freeway without access were identified. The precise orientation and location of the future access roads (dashed lines) are not a critical element of the plan. Their existence is postulated for purposes of traffic modeling; however, their precise location and orientation can wait for actual development planning. What is critical is to establish the intersection influence areas where arterials intersect the freeway system. With this intersection influence area identified, the "nodes" where the access roads intersect the arterial roadways may be fixed. 


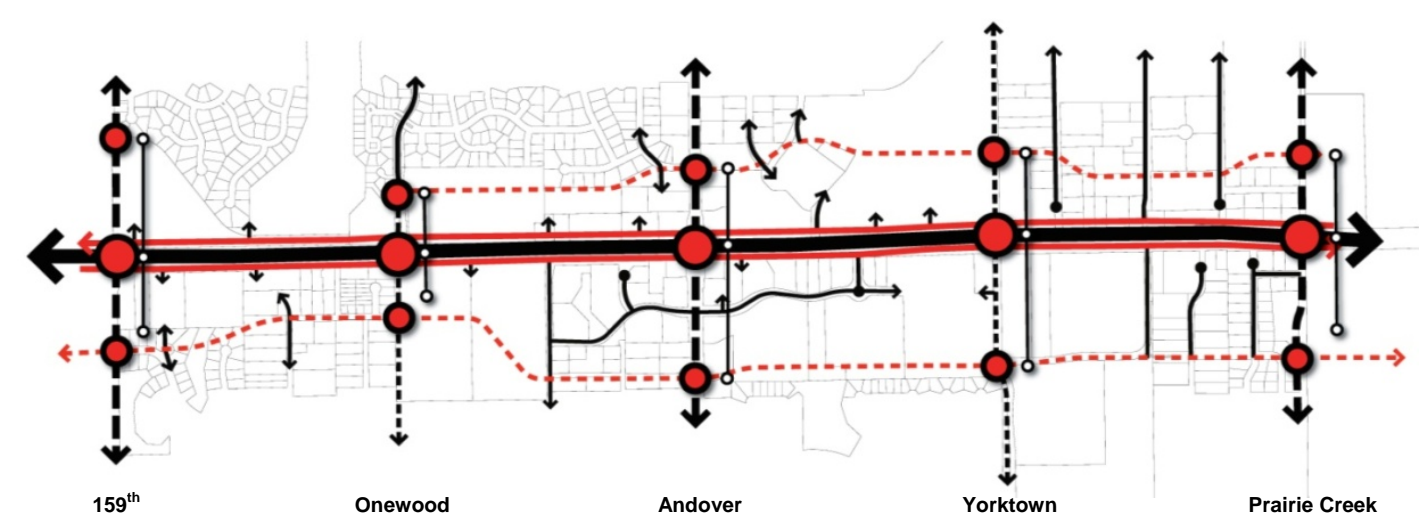

Figure 7: Intersection/Interchange Nodes

A single interchange option was analyzed at US-400 and Andover Road; however, projected traffic volumes could not be accommodated at acceptable levels of service given the constraints of cross-section established. An "extended-diamond" interchange option was analyzed that would have local traffic exiting US-400 at either $159^{\text {th }}$ Street or Prairie Creek, but the perceived loss of accessibility, plus the difficulty of handling predicted traffic volumes at Andover Road made this option impractical. The three interchange node option (159 ${ }^{\text {th }}$ Street, Andover Road, and Prairie Creek) was identified as the most feasible option. The influence areas of these interchange areas were analyzed considering a traditional $d_{1}+d_{2}+d_{3}$ analysis. The $d_{1}$ (perception-reaction) distance is not considered to be significant given the low expected operating speeds (likely below $50 \mathrm{kph}$ in the peak hours). Likewise, the $d_{2}$ (deceleration-maneuver) distance is not considered significant given the low expected operating speeds. The $d_{3}$ (queue storage) distance, however, is significant, and the VISSIM model is relied upon to establish the queue storage requirement for a $95 \%$ back-of-queue confidence. The nodes for the fully-directional intersections that are the access roads are fixed beyond this queue storage area. This separation of conflict areas is critical to the safety and sustainability of the corridor.

\section{ACCESS MANAGEMENT PLAN}

\subsection{Future Interchange and Intersection Locations}

The three future interchange locations between arterials and the freeway corridor were identified at $159^{\text {th }}$ Street, Andover Road, and Prairie Creek Road based upon future traffic demand. Two other locations were identified at Onewood Drive and Yorktown Road where these arterials will overpass the freeway corridor without access. Figure 8 below shows the preliminary layout of a typical arterial interchange area with access. Figure 9 shows the preliminary layout of a typical arterial overpass without access. 


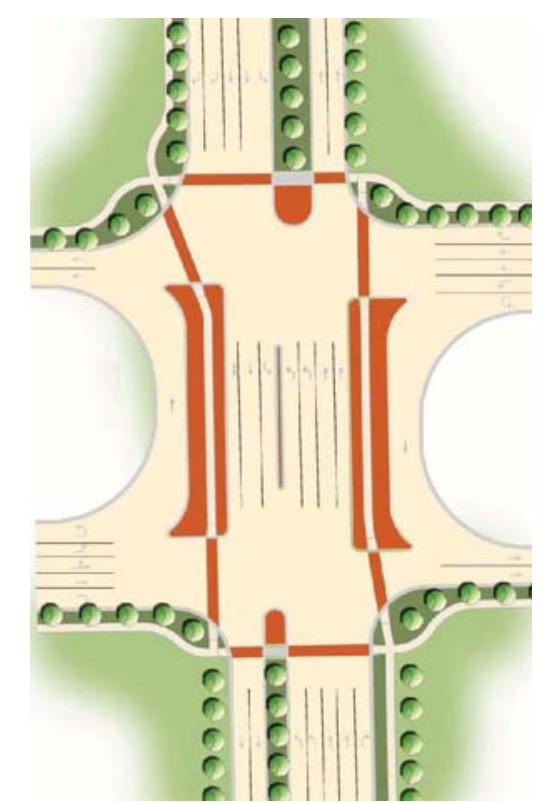

Figure 8: Arterial Street Interchange Layout

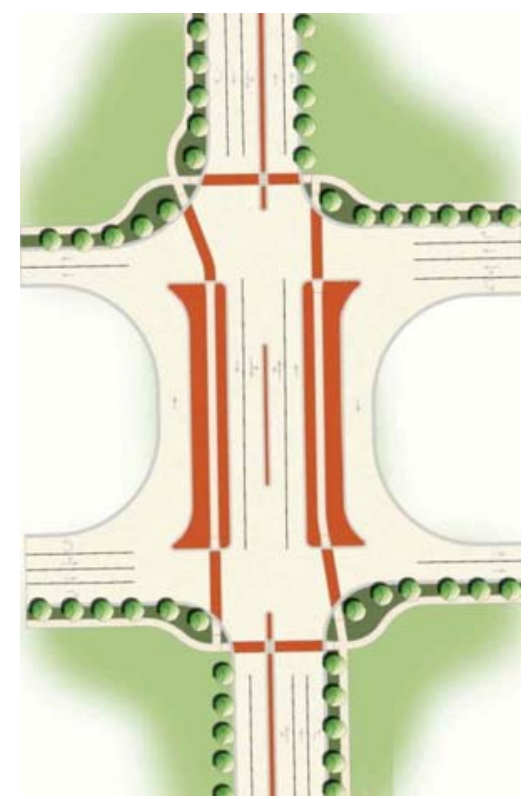

Figure 9: Arterial Overpass Layout

\subsection{Accessibility - Mobility - Market Area}

An ambitious corridor plan such as this virtually assures objection and concern from a variety of quarters, most notably that of the business community. It is a commonly held belief of business owners that direct convenient access is a critical element of business success. It is widely believed that we can have either:

- A safe, efficient, well-managed transportation system, or

- economic development and a business-friendly climate,

but these two conditions cannot coexist. Nothing could be further from reality, however, and safe well managed corridors tend to outperform the community as a whole in terms of economic vitality. One of the most powerful illustrations of this is the way in which access management sustains the market penetration of businesses through the maintenance of efficient flow of traffic. A transportation network's ability to safely and efficiently carry traffic is undermined by inappropriate numbers, locations, and designs of access points and intersections. The publication of the National Cooperative Highway Research Program (NCHRP) titled "Impacts of Access Management Techniques" (NHCRP Report 420) indicates that each intersection added to an arterial corridor can be expected to increase the crash rate on the corridor by about 4\%. The operating speed of an arterial corridor can also be expected to decrease by about $0.5 \mathrm{kph}$ for each intersection added. As the "side friction" generated by these intersections and access points builds, the prevailing speed of the traffic flow on the network decreases. As speed decreases, travel time (speed's inverse) increases. As travel time increases, market area shrinks. This is the physical mechanism through which poor access management results in economic deterioration. This relationship between speed and market area is explained in the Transportation Research Board's Access Management Manual, as depicted in Figure 10 below. 


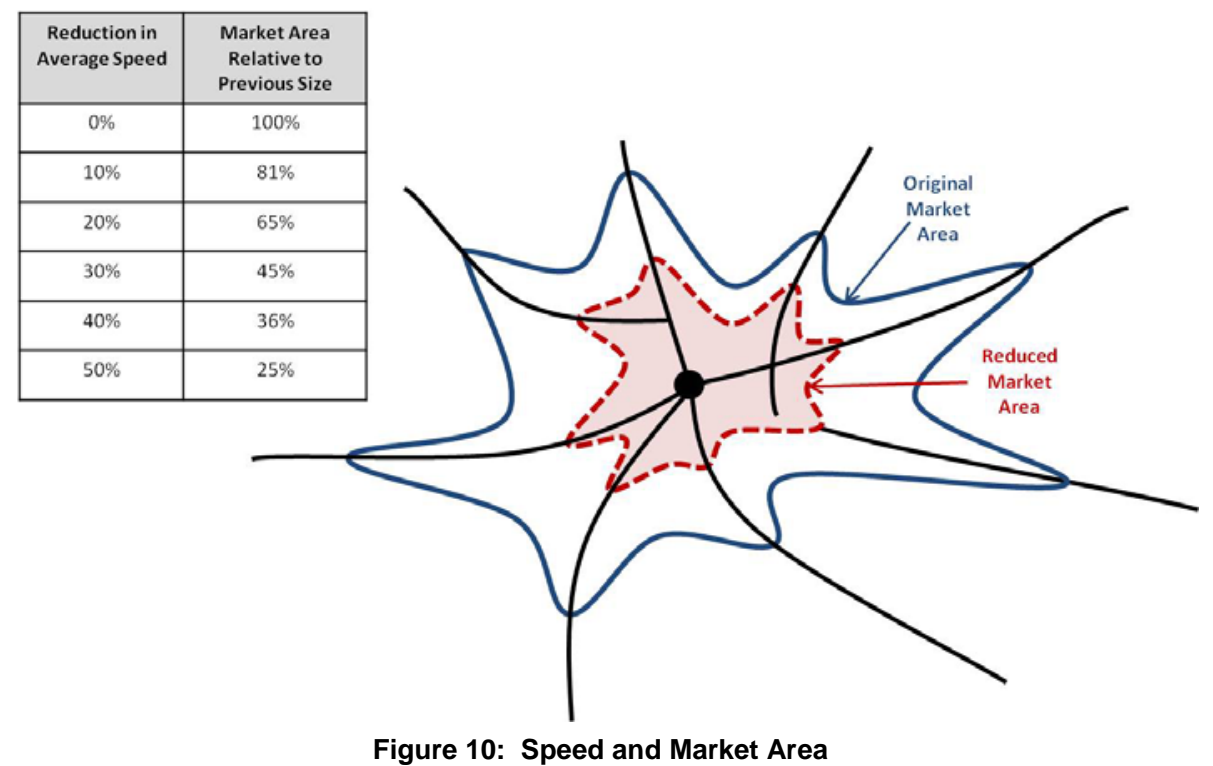

As the above figure indicates, the relationship between network speed and market area is not a 1:1, linear relationship. Rather, research indicates that the relationship operates according to the ratio of the squares of the speeds. In other words, a drop in average network speed from 40 kilometers per hour to 20 kilometers per hour indicates a 50\% drop in prevailing speed. However, as illustrated in Table 1 below, comparing the squares of these speeds indicates that a $50 \%$ drop in operating speed leaves only $25 \%$ of the original market area.

\begin{tabular}{|c|c|c|c|c|}
\hline \multicolumn{5}{|c|}{ Table 1 } \\
\hline Original Speed & & Square & & Ratio of the Squares \\
\hline $40 \mathrm{kph}$ & & 1600 & & \\
\hline Reduced Speed & & Square & & \\
\hline $20 \mathrm{kph}$ & & 400 & & $4: 1$ or $\quad 25 \%$ \\
\hline
\end{tabular}

No business can expect to remain open with only $25 \%$ of its original market area. Therefore, we conclude that careful corridor planning, with particular attention to the number, location, and design of intersections and access points is critical if we are to sustain economic activities.

\section{LAND USE (DEVELOPMENT) PLAN}

\subsection{Supporting Greater Land Use Densities}

With the transportation network established, and the access plan in place, we are able to develop a land use plan. It is critical that the densities and mixes of the proposed land uses not generate traffic volumes that will overwhelm the planned transportation system. This became an iterative process through which densities and uses were attributed to the various transportation nodes on the network, and the resulting volumes checked against capacity constraints and level of service requirements. 


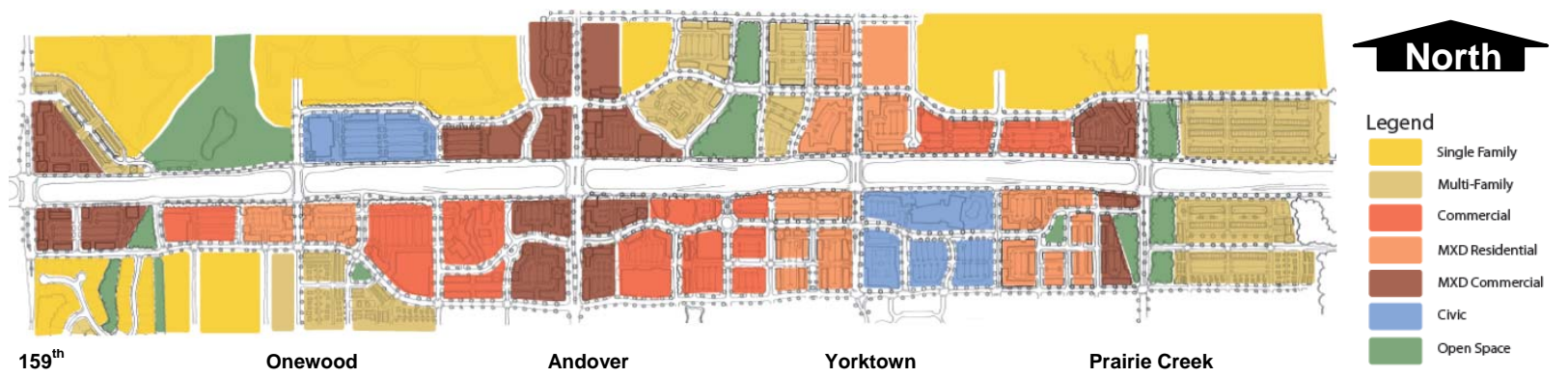

Figure 11: Future Land Use Plan

This land use plan is the culmination of both quantitative analysis (traffic forecasting, access management, etc.) and qualitative analysis (social priorities, vision of success), and results in a transportation plan that preserves the safety and operational efficiency of the transportation network while simultaneously providing the greatest and most sustainable degree of tax base and quality of life. It is interesting to note that the identified transportation network and access plan allow densities of land use that are much higher than is typical for this part of the U.S.. This greater density (in the form of higher floorarea-ratios) means greater potential for tax revenues.

\subsection{Areas of Greatest Potential}

The vast majority of the study area will undergo development or re-development in the amount of time required to fully construct the indicated transportation system. Therefore, positive guidance and careful stewardship of this corridor is both critically important, and exceptionally challenging. There are a few areas, however, that provide unprecedented potential and merit special consideration.

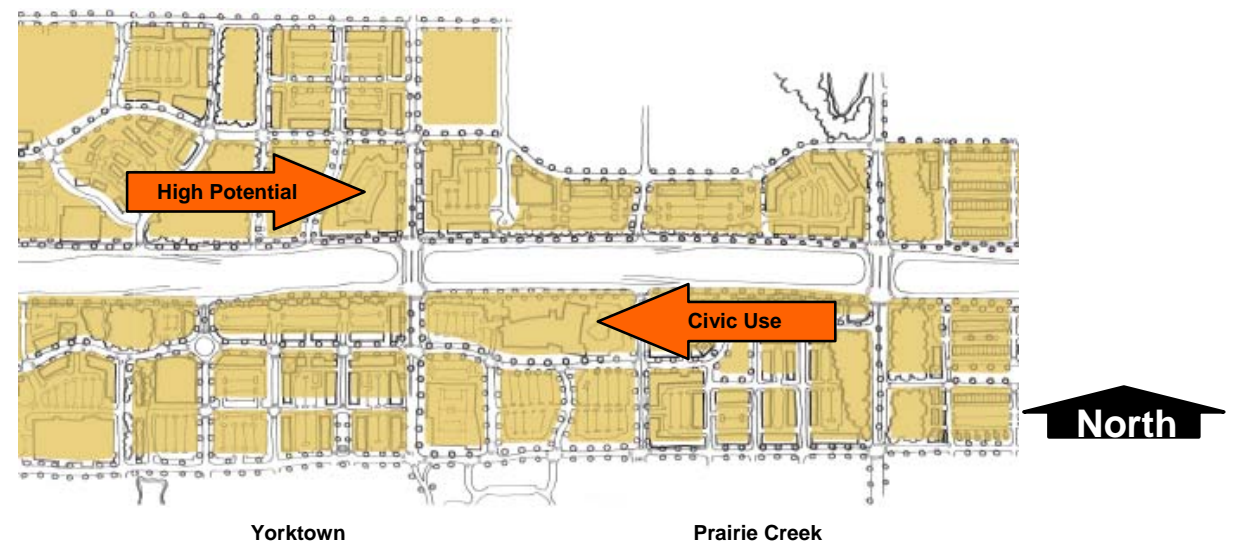

Figure 12: Areas of High Economic Potential

One particular area, shown as "High Potential" in Figure 12 above, holds tremendous potential. The Yorktown arterial corridor will overpass the freeway corridor without access, providing some degree of protection for multi-family residential and residential mixed use developments to the north of the freeway. The depressed elevation of the freeway also encourages visibility of the YMCA (civic) complex to the south of the corridor and provides good pedestrian and bicycle access to patrons of the YMCA. Simultaneously, this area provides access to the freeway corridor via the interchanges that are equidistant to the east and west. It is the Team's opinion that this area provides the best balance of vehicular and pedestrian accessibility as well as the best overall opportunities for sustainable, higher density development and the best overall quality of life attributes. 
In conclusion, this corridor plan begins with clear statements of social policy and measures of effectiveness that identify and prioritize the goals of the key stakeholders, and result in a clear vision of a successful corridor. This qualitative effort then supports the quantitative analyses that result in a transportation plan that will support and sustain a land use plan. That transportation systems respond much more slowly to changing conditions than do the economic forces that drive land uses means that transportation professionals find themselves in a losing game of attempting to respond to changing demands. Thus, it is advantageous to all stakeholders if the transportation elements can be fixed in plan, then the land uses guided to take advantage of the transportation network. This is due to the fact that, while transportation and land-use exists in a supply and demand relationship just as any economic system, changes in land use (demand) happen much more rapidly than corresponding changes in transportation (supply). This results in transportation networks becoming overburdened, congested, and unsafe and leads to significant challenges of implementation. This also results in significant future transportation improvements becoming much more difficult and expensive. On the US-400 corridor in the city of Wichita, approximately 5 kilometers to the west of the project area, a retrofit of a major intersection to a grade-separated interchange (very similar to the US-400 / Andover Road intersection near the middle of the Project area) was very disruptive. The project resulted in numerous acquisition of improved properties, relocation of businesses, and cost in excess of $\$ 100$ million dollars per kilometer according to some estimates.

\subsection{Implementation of the Corridor Plan}

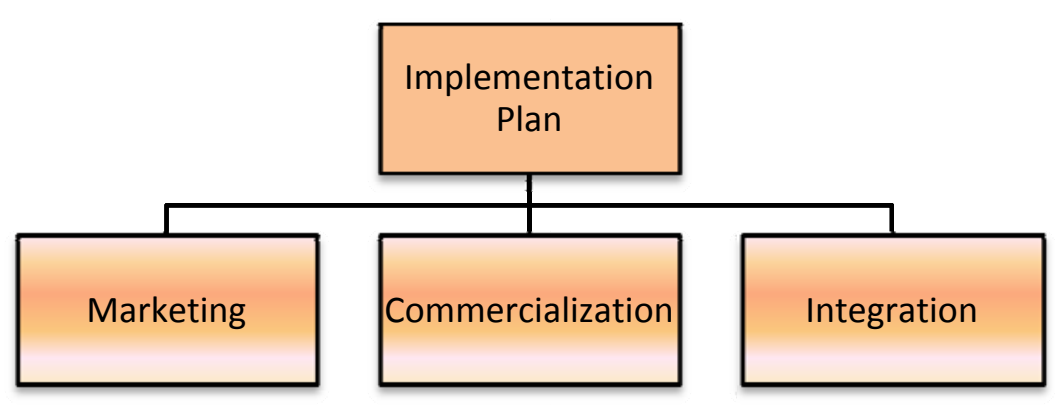

Figure 14: Elements of an Implementation Plan
Implementation of this plan will require a complete package of marketing, commercialization, and integration that is a significant effort on its own. The National Highway Institute of the US Federal Highway Administration visualizes this effort as shown in Figure 13 to the left. It is important that this corridor plan be marketed

effectively to all of the target audiences that were identified in the corridor study. The Team has also recommended that commercialization (in the form of public/private partnerships between regulatory agencies and private industry) be employed to assist in the marketing effort. It will also be necessary to integrate the corridor plan into the various regulatory frameworks that will exert influence over this corridor. At a minimum, this must include the following:

- Incorporation of the Plan into the City's Comprehensive Plan

- Incorporation of the Plan into the Region's Transportation Improvement Plan

- Incorporation of the Plan into the State's Access Management Policy

- Approval of the Plan by the Federal Highway Administration

There are also regulations such as Zoning Codes, and other land use regulations that will play a part in the implementation of this plan.

\subsection{Public/Private Partnerships in Implementation}

Though not a technical challenge, the notion of "partnering" on the marketing and development of a corridor between government and private industry poses a specific set of 
challenges. The Team has recommended a shared-risk/shared-reward approach and has suggested formal partnerships between the governments and various real property brokers that have a presence in the area.

The land use plan for this corridor is a significant departure from the norm in terms of density, and in terms of mixing of land uses. It is likely that vigorous marketing of the corridor to a national audience of buyers will be required. Fortunately, there are at least two real property development firms in the area that are part of national networks of brokers and developers. It is anticipated that these private sector partners may be interested in defraying a great deal of marketing costs in exchange for opportunities for sales commissions and other revenues. This element still requires a great deal of analysis and development.

\subsection{Future Challenges}

The single biggest challenge to the implementation of this plan is the amount of time that will be required. Forward movement has begun with this study process, but maintaining that momentum over the decades that will ensue is expected to be particularly challenging. Social and political priorities may well change, and the momentum for this Plan may wane. This risk has been considered by the stakeholders, and it is believed that the risk must be taken. Any progress made in the implementation of this Plan leaves all stakeholders in better position than without the effort. Careful documentation of progress, and celebration of successes will help mitigate this risk, and the stakeholders are already involved in the early stages of implementation.

\section{REFERENCES}

National Highway Institute, 2007 NHI 133078: Access Management, Location, and Design National Highway Institute, $2010 \mathrm{NHI}$ 134073: Leap not Creep, Accelerating Innovation PB, Huffman Corridor Consulting, et.al., 2011City of Andover, US-54/400 Corridor Study Transportation Research Board, 2003, Access Management Manual NCHRP 420 - Impacts of Access Management Techniques 